\title{
The Instructional Efficacy of Strategy-based Instruction via Electronic Portfolio Assessment in Improving Reading Proficiency of Iranian Intermediate EFL Students
}

\author{
Ramin Vaezi ${ }^{1}$ \\ Mansoor Koosha² \\ 1 Department of Foreign Languages, Isfahan (Khorasgan) Branch, Islamic Azad University, Isfahan, Iran \\ *Email: ramin.vaezi@khuisf.ac.ir; ramin2003@hotmail.com \\ 2 Department of Foreign Languages, Isfahan (Khorasgan) Branch, Islamic Azad University, Isfahan, Iran
}

Doi:10.5901/mjss.2016.v7n2s1p476

\section{Abstract}

This article tries to explore the instructional efficacy of strategy-based instruction via electronic portfolio assessment (Web plus $C D-R O M)$ in improving reading proficiency of Iranian intermediate EFL students. To do so, from the population of male EFL learners studying English at a language institute in Esfahan, a sample of 60 was selected by administrating a Nelson Proficiency Test (Nelson, 1976) to ensure that they are homogeneous in terms of language proficiency. Afterwards, the participants were divided into three equal groups; namely, two experimental and one comparison group. The comparison group was taught using traditional methods of teaching reading comprehension and the experimental groups were taught using four reading strategies (highlighting a text, parsing sentences by putting slashes (I) into sense units, using visual aids and pictures to understand the outline of a text, and drawing cluster diagrams to link the ideas within the text to understand the whole text). After the treatment, a posttest was administered. The mean scores of the comparison and both experimental groups on the posttest revealed that language learners' mean score in the experimental groups was significantly higher than language learners' mean score in the comparison group. This means that reading instruction, which was strategy instruction, was more effective in improving readers' reading proficiency. Another goal of this study was investigating the instructional efficacy of electronic portfolio assessment while using reading strategies. A weblog was designed to collect the participants' tasks to be shown to their classmates to see the result of strategy training, using the strategies, and the progress of the participants during the study. To sum up, the results of this article state that foreign language pedagogy, especially for adult and young adult English learners, would reap the benefits of the inclusion of explicit and direct strategy instruction within electronic portfolio assessment.

Keywords: Alternative Assessment, Authentic Materials, Electronic Portfolio Assessment, Portfolio Assessment, Reading Proficiency, Reading Strategy, Strategy-based Instruction

\section{Introduction}

The use and power of reading in helping learners' general language proficiency and reading skills in content learning have been widely known among reading researchers and literacy educators (Zhang, 2008). According to some writers (e.g. Day and Bamford, 1998) when reading abilities are improved, second or foreign language learners can tackle authentic reading materials confidently. In some studies on students learning to read, some findings have been reported that clarify the teachability of strategies, such that students can have control on it by their metacognitive awareness which is available for use to ameliorate reading proficiency (Zhang, 2008).

Many researchers have also offered evidence that learner awareness or metacognition of aspects applying for successful second language learning in general and reading comprehension in specific, including learning strategies, is closely correlated to learners' success (e.g. Anderson, 1978; Chamot et al., 1999; Oxford, 2001; Wenden, 1991; Zhang, 2002). Flavell (1992) and Pressley (2002), especially, argue against giving greater attention to the role of metacognition in helping learners' self-regulation of their own learning. They claim that learner metacognition, i.e. their awareness of and cognitive control and regulation over learning can improve learning efficiency and self-efficacy (Alexander, 1995; Veenman and Beishuizen, 2004).

Reading strategies can be best described "as plans for solving problems encountered in constructing meaning" (Duffy, 1993, p. 232). They vary from bottom-up vocabulary strategies, such as looking up an unknown word in the dictionary, to more comprehensive efforts, such as linking what is being read to the reader's background knowledge. Besides, reading strategies can be taught to learners, and when taught, strategies' assistance can amend student 
accomplishment on tests of comprehension and recall (Richards \& Renandya, 2002).

Considering all the requirements in reading instruction and assessment, EFL learners and instructors need to break new ground and venture innovative practices in which all the process of learning how to read is documented and assessed by both instructors and learners themselves. Most important, instructors are required to weave assessment into instruction and contribute opportunities for learners to utilize evaluation skills as a learning task (Chen, 2006). Portfolios provide a commanding tool to enhance the instruction and assessment, addressing educators' concerns about authentic assessment, documentation of academic progress, and instructor and learner involvement (Richards \& Schmidt, 2002). If instructors and scholars are to change and improve education, it will require involving learners and making them think meaningfully and strategically about learning. Learners must be active and capable of dealing with difficult tasks in creative and imaginative ways (Abrami and et al., 2008).

Abrami et al. (2008) found that student-centered learning is an approach in which technology plays a crucial role like a powerful instrument in improving educational change. Among these technological developments, electronic portfolios are the most interesting and exciting ones because they support students and teachers' self-regulation and core educational competencies, especially literacy skills.

A portfolio can be best defined as, "A purposeful collection of work that provides information about someone's efforts, progress or achievement in a given area" (Richards \& Schmidt, 2002, p. 406). On the other hand, electronic portfolios are collections of students' work that maybe posted online (called 'web-folios') or saved onto a CD-ROM. They help students in sharing their work with a larger audience by giving them a wider audience outside the classroom, offering authentic assessment tools, motivating students, and contributing to their development (Ali, 2005).

Thus, This article attempts to clarify whether providing reading strategies via an electronic portfolio frame to Iranian EFL learners helps them to move beyond the traditional stages of reading assessment; that is more process-based rather than product-based one, which leads the language learners to self-assessment and autonomy and also to utilize these strategies which are accompanied with technology that presumably would be fruitful in computer-based exams, like IBT tests, which deals with technology and English at the same time. Taking a look at above mentioned problems and requirements for the reading instruction makes one ponder over the questions which probably arise as follows:

1. Does strategy-based instruction have any statistically significant instructional efficacy on the reading proficiency of Iranian EFL learners in comparison with a non strategy-based one?

2. Does electronic portfolio assessment with a strategy-based instruction have any statistically significant instructional efficacy on the reading proficiency in comparison with paper-based portfolio assessment with strategy-based instruction?

\section{Statement of the Problem and Purpose of the Study}

The researchers, as English instructors in different centers and levels, have discerned that Iranian EFL learners carry out reading tasks with difficulty since they are not acquainted with how to deal with this skill, are not versed in using strategies in the reading task, and are merely concerned with figuring out new vocabularies and expressions in the text. Another crucial issue which is the researchers' consideration is reading assessment, which has traditionally made use of Wh-questions after each text, which the learners ought to answer. This method is popular in many reading classes and also in reading assessment. Students read a text and after that answer some questions related to the text, which questions are related to grammatical points, vocabulary understanding, and comprehension of the text. So, it is hoped that a type of assessment which is based on web plus CD-ROM and called electronic portfolio would empower the learners to utilize the strategies which have been taught during their English course to promote the learners' reading proficiency and also facilitate an authentic assessment for Iranian EFL learners. Therefore, the goal of this paper is to determine whether strategy-based training via electronic portfolio assessment (web plus CD-ROM) has any statistically significant instructional efficacy on the reading proficiency of Iranian EFL learners.

\section{Significance of the Study}

The results of the present paper can help the Iranian EFL students decide to apply electronic devices such as their personal computers, computer softwares, and other technological devices within their course and tasks. The participants in this study have tried to document whatever they have done during their reading course via electronic form of portfolio as a good instrument to assess their learning, critical thinking, autonomy, and deal with problems. The importance of this research is in a way of using reading strategies to increase the language learners' reading comprehension while they are exposed to technological devices, such as personal computers, connecting to internet, posting their tasks to a weblog, 
and storing their activities on CD-ROM.

However, relatively few studies have reported on the utility of strategy use on various levels of reading comprehension (Brantmeier, 2005). Another crucial significance of this research is paving the way for the learners to figure out IBT tests and tasks that technology is a prerequisite device to accomplish, since they apply technology to enhance their ability in the reading skill. As a result, this survey may expand practitioners' use of the electronic portfolios to develop the learners' motivation in the reading skill and may also become aware of the importance of training strategic readers and revise their current theory and practice in reading comprehension classes within technological devices.

\section{Materials and Methods}

\subsection{Participants}

The participants selected for this article were chosen from students who enrolled in the intermediate level of a language school in Esfahan, Iran. They were considered to be at the intermediate level according to the institute's placement test scores and due to their scores in the prior course. The participants were adults, their ages ranged from 18 to 34 , and they were all males. The groups were intact and not randomly selected. However, the Nelson proficiency test (Nelson, 1976) was administered to determine their level of proficiency and find out if the experimental and the comparison group were significantly different or not.

\subsection{Instruments}

Seven types of instruments were used in this paper; the Nelson Proficiency test (Nelson, 1976), the Skill-based Strategy Inventory (SBSI) reading strategies questionnaire (Oxford, 2001), a researcher-made reading comprehension test as pretest and posttest, the teaching materials, an achievement test as mid-term test, and a weblog designed by the researchers.

\subsection{Pilot Study}

The Reading Comprehension Test--pretest and posttest--was piloted to ensure the validity, reliability, clarity of the rubrics, unambiguousness and misprint corrections of the test. The environment in which the experiment was conducted was similar to the real one. Forty participants, who were similar to the main sample, i.e. with regard to their English language proficiency level, gender, and age completed the tests. No technical problems arose during the pilot study. However, the data and feedback were used to set the time needed for the test administration and administration condition for the study.

Table 1 depicts the descriptive statistics for the Nelson and Reading Comprehension Test (RCT) administered during the pilot study.

The K-R21 reliability indices for the Nelson and Reading Comprehension Test were .85 and .70 respectively.

Table 1. Descriptive statistics for the Nelson Proficiency Test and Reading Comprehension Tests (RCT = Reading Comprehension Test)

\begin{tabular}{|l|c|c|}
\hline \multicolumn{3}{|c|}{ Statistics } \\
\hline & Nelson & RCT Pilot \\
\hline Mean & 32.4000 & 20.4000 \\
\hline Std. Deviation & 9.01246 & 5.05884 \\
\hline Variance & 81.224 & 25.592 \\
\hline Skewness & -.166 & -.471 \\
\hline Std. Error of Skewness & .337 & .337 \\
\hline Kurtosis & -.727 & -.440 \\
\hline Std. Error of Kurtosis & .662 & .662 \\
\hline Minimum & 15.00 & 8.00 \\
\hline Maximum & 48.00 & 28.00 \\
\hline K-R21 & .88 & .77 \\
\hline
\end{tabular}




\subsection{Instructional Materials}

In this paper, the researchers needed to focus on the reading skill. To do so, the passages used in this study were chosen from the Readers' Digest magazine. This was done to motivate the participants to take part in the class activities efficiently. These kinds of passages are called authentic reading and according to Nuttall (1996) they are written to use by the foreign language community, not for language learners. Since the teaching materials were selected by the researchers, the readability of the coursebook's texts was considered as the basis of choosing the passages according to the level of the participants' reading proficiency. To do so, the researchers assessed the coursebook texts' readability, which was done through Word Processor Microsoft 2010, They measured the coursebook texts' readabilities and chose those texts with a readability within -1 and +1 standard deviation of the coursebook texts' readability. Eight texts were chosen in this way. Four texts were practiced in class and the other four texts were assigned as homework for the participants to practice at home.

Moreover, an achievement test was administered as midterm test to be ascertained about possible impacts during the study. After answering the questions the researchers asked the participants to express the way of using reading strategies while they were answering the questions and their classmates could comment on the way they used the reading strategies during the test. Apart from the aforesaid instruments, a weblog was designed to collect the participants' tasks to be shown to their classmates to see the result of strategy training, using the strategies, and the progress of the participants during the study. The goal was to establish cooperation among participants. In this way the participants cooperated with each other, which was one of the study's aims to enhance reading proficiency by utilizing electronic portfolio assessment. Since this study was based on web plus CD-ROM electronic portfolio, the participants compiled their tasks on recordable CDs in order to see their own progress during the study. Also to investigate the impact of electronic portfolios, the researchers had another experimental group, which used traditional (i.e. paper-based) portfolios.

\section{The Main Study}

The researchers administered a standardized Nelson Proficiency Test to homogenize the participants with regard to their proficiency level in English and 60 students with scores falling between one standard deviation above and one standard deviation below the mean were selected as the participants of this study. Afterwards, participants were divided into two groups as the two experimental groups in which working on reading strategies via portfolio assessment (web plus CDROM) and traditional portfolio i.e. paper-based portfolio and the comparison group in which working on reading comprehension with no aids of portfolio and reading strategies. Afterward, the pre-test was administered to three groups one week before the intervention. The participants were asked to read and answer 30 multiple choice questions followed by five passages.

In this paper, three groups were intended to be exposed to the instruction of reading. The strategies were limited to reading; and they shared many other things including similar field of study, age and sex categories, the same reading materials and the same reading proficiency tests with similar questions, as well as equal period of class reading activities. In fact, the only factor that made a distinction between them was the various kinds of educational method for reading comprehension. In the experimental groups, after the teacher's overt teaching and using of the reading strategies, the students were required to follow suit and apply similar strategies while reading the remaining part of the text. Students were encouraged to take greater risk and became volunteers in reading the texts and try using those strategies themselves.

One of the researchers allocated three days a week to teach the strategies and also portfolios, both paper and electronic-based. Each session consisted of 90 minutes, which five to ten minutes were specified for teaching reading strategies and twenty to twenty five minutes to reading.

\subsection{Pre-test}

After choosing three homogeneous groups as comparison and experimental, the researchers administered the reading strategies questionnaire to three groups to be sure that the participants were not familiar with the reading strategies which the researchers were going to introduce them during the study. The skill-based strategy inventory (Oxford, 2001) was used in this study. It was scored and afterward the participants whom they were not familiar with the strategies were involved in the study and those who were familiar with the strategies took part in the survey but were not included in the study. Afterward, a reading comprehension test, elaborated on in the instrumentation section, was administered as pretest. 


\subsection{Experimental Groups}

On the first day of the course via a checklist introduced the tasks that the participants were supposed to do according to the electronic portfolio rubrics, one of the researchers introduced the participants to the portfolio project, which was the goal of the course. He explained that it was crucial that they save everything they did. Also he provided a condition in which the portfolio did not become an end product towards which students were self-consciously aiming their efforts for a grade. Instead, the portfolio grew out of their attention to reading. To do so, the researcher provided participants with a handout that explained the nature of the portfolio and told them why he was asking them to do it. Since the focus of this study was on the electronic form of portfolios, the researchers had two experimental groups, one of which prepared paper-based (traditional) portfolios and the other one prepared electronic portfolios on recordable CDs, paying attention to the rubrics.

Four reading strategies were taught to the participants during the course as follows:

1. Highlighting a text: This active reading strategy, links concept of highlighting key words and phrases in a text and annotating those highlights with marginal notes.

2. Parsing sentences, by putting slashes $(\zeta)$ into sense units (to grasp the main components of each sentence easily.

3. Using visual aids and pictures to realize the outline of a text.

4. Drawing cluster diagrams to link the ideas within the text to understand the whole text.

5. This study was conducted during 15 sessions, and the last session consisted of a review of the all introduced strategies.

In the paper-based portfolio group, each 3 sessions were allocated to one of the aforesaid strategies. A new strategy was introduced in one session through the passage, prepared by the researchers, and explained in the class, and another passage was assigned for the participants to do for the next session at home and by use of traditional portfolios at home. The third session, participants exchanged their paper-based portfolios in the class to comment on. The same procedures were run in electronic-based portfolios, using CD-ROMs and then posting the participants' tasks to the weblog. In the electronic-based group, participants uploaded their activities on the weblog before the third session. This way, they could find out their faults during their activities at home, and also could compare their tasks with their classmates. The similarity between the two groups was that both kept files which were called 'portfolios' and the difference was that one group kept the files in paper folders and the other one kept files on CDs and the weblog, which was designed by one of the researchers.

\subsection{Comparison Group}

In this group also, the same criteria and goals were discussed and also the same teaching materials were provided for the participants, but the difference was that in this group the same teaching materials were taught without any special strategies and technological aids; that is, the participants in this group read the same texts in the class through the usual and traditional way of reading and they did the same homework at home on reading. Everything in this group was the same as the other two groups, except for the strategies that were not taught, and the teaching materials, which they were supposed to practice as homework were copied on CDs for them by the researchers.

\subsection{Posttest}

The researchers administered the same researcher-made pre-test which was administered at the beginning of the study to see the utility of the intervention and procedures during the study. In order to lessen test-wiseness, the researchers changed the physical appearance of the test, by changing the order of questions and also the order of the passages. Afterwards, the skill-based strategy inventory was given to the participants to see how they used the strategies and whether or not they were effective. After scoring the questionnaire, the result was compared with the scores before the treatment, to see the similarities and differences before and after treatment. The pre- and posttest were administered at the same time to the experimental and comparison groups. 


\section{Data Analysis}

\subsection{Statistical Analysis for the Pre- and Posttest Questionnaires}

Table 2 depicts the descriptive statistics for the pre-test and posttest questionnaires.

Table 2. Statistics descriptive of the Pre and Post Questionnaire

\begin{tabular}{|l|c|c|}
\hline \multicolumn{2}{|c|}{ Statistics } \\
\hline Mean & Pre-test Questionnaire & Posttest Questionnaire \\
\hline Std. Deviation & 63.4000 & 87.8667 \\
\hline Variance & 11.80 & 11.94162 \\
\hline Skewness & 139.421 & 142.602 \\
\hline Std. Error of Skewness & .070 & -.483 \\
\hline Kurtosis & .427 & .427 \\
\hline Std. Error of Kurtosis & .396 & -1.083 \\
\hline Minimum & .833 & .833 \\
\hline Maximum & 48.00 & 63.00 \\
\hline K-R21 & 76.00 & 103.00 \\
\hline
\end{tabular}

By looking at table 2, we can infer that the distributions of the two questionnaires did not deviate from the normal curve.

\subsection{Statistical Analysis for the Pre-test Reading Comprehension}

It is worth mentioning that the three groups enjoyed homogeneous variances on the pre-test reading comprehension test, that is to say, they had been selected from the same population with no marked differences between their distributions. As displayed in Table 4 the Levene's test of homogeneity of variances statistic was $.290(p=>.05)$. Since the probability associated with the Levene's test was higher than the significance level of .05 , it could be inferred that the three groups enjoyed the homogeneity of variances.

Table 3 depicts the descriptive statistics for the three groups on the pre-test of reading comprehension.

Table 3. Descriptive Statistics of the Pre-test Reading Comprehension by Groups

\begin{tabular}{|c|c|c|c|c|c|c|c|c|}
\hline & & & Std Reviatio & $\operatorname{std}$ Frror & $95 \%$ Confidenc & nterval for Mear & & \\
\hline & $\mathrm{N}$ & Mean & Std. Deviatıor & Sta. Error| & Lower Bound & Upper Bound & & \\
\hline Comparison Group & & 21.6667 & 3.19842 & .58395 & 20.4724 & 22.8610 & 15.00 & 27.00 \\
\hline Experimental Group (Electronic-based Portfolio) & & 21.0667 & 2.93906 & .75886 & 19.4391 & 22.6943 & 16.00 & 26.00 \\
\hline Experimental Group (Paper-based Portfolio) & & 21.8667 & 2.89992 & .74876 & 20.2607 & 23.4726 & 17.00 & 26.00 \\
\hline Total & & 21.5667 & 3.02737 & .39083 & 20.7846 & 22.3487 & 15.00 & 27.00 \\
\hline
\end{tabular}

Table 4. Levene's Test of Homogeneity of Variances Pre-test

\begin{tabular}{|c|c|c|c|}
\hline Levene Statistic & df1 & df2 & Sig. \\
\hline .290 & 2 & 57 & .750 \\
\hline
\end{tabular}

Furthermore, a one-way ANOVA was administered to compare the mean scores of the one comparison group and the two experimental groups on the pre-test of reading comprehension. The F-observed value (Table 5) for comparing the three groups mean scores on the pre-test was .287 $(p=.751>.05)$.

Table 5. One-Way ANOVA Pre-test Reading Comprehension by Groups

\begin{tabular}{|l|c|c|c|c|c|}
\hline & Sum of Squares & Df & Mean Square & F & Sig. \\
\hline Between Groups & 5.400 & 2 & 2.700 & .287 & .751 \\
\hline Within Groups & 535.333 & 57 & 9.392 & & \\
\hline Total & 540.733 & 59 & & & \\
\hline
\end{tabular}


By looking at table 5, it could be infered that there was not any statistically significant difference between the one comparison group and the two experimental groups' (Paper-based and Electronic-based Portfolios) mean scores on the pre-test of reading comprehension.

\subsection{Statistical Analysis for the Posttest Reading Comprehension}

It should be mentioned that the three groups enjoyed homogeneous variances on the posttest reading comprehension test, that is to say, they had been selected from the same population with no marked differences between their distributions. As depicted in Table 7 the Levene's test of homogeneity of variances statistic was $1.04(p=>.05)$. Since the probability associated with the Levene's test was higher than the significance level of .05 , it could be concluded that the three groups enjoyed homogeneity of variances.

Table 6 depicts the descriptive statistics for the three groups on the posttest of reading comprehension.

Table 6. Descriptive Statistics Posttest Reading Comprehension by Groups

\begin{tabular}{|c|c|c|c|c|c|c|c|}
\hline & & & & 95\% Confidence & nterval for Mea & & \\
\hline & |N| Mean & Sta. Deviatıon & & Lower Bound & Upper Bound & & axim \\
\hline Comparison Group & 3024.8000 & 2.35475 & .42992 & 23.9207 & 25.6793 & 20.00 & 29.00 \\
\hline Experimental Group (Electronic-based Portfolio) & 1526.4000 & 1.72378 & .44508 & 25.4454 & 27.3546 & 22.00 & 29.00 \\
\hline Experimental Group (Paper- based Portfolio) & 1526.2000 & 1.78085 & .45981 & 25.2138 & 27.1862 & 23.00 & 29.00 \\
\hline Total & 6025.5500 & 2.18178 & 28167 & 24.9864 & 26.1136 & 20.00 & 29.00 \\
\hline
\end{tabular}

Table 7. Levene's Test of Homogeneity of Variances Posttest

\begin{tabular}{|c|c|c|c|}
\hline Levene Statistic & df1 & df2 & Sig. \\
\hline 1.042 & 2 & 57 & .360 \\
\hline
\end{tabular}

A one-way ANOVA was run to compare the mean scores of the one comparison group and the two experimental groups (Paper-based Portfolio and Electronic-based Portfolio) on the posttest of the reading proficiency test so as to probe the two research questions posed in the present research. The F-observed value (Table 8) for comparing the three groups mean scores on the posttest reading comprehension was $3.932(p=.025<.05)$.

Table 8. One-Way ANOVA Posttest Reading Comprehension by Groups

\begin{tabular}{|l|c|c|c|c|c|}
\hline & Sum of Squares & Df & Mean Square & F & Sig. \\
\hline Between Groups & 34.050 & 2 & 17.025 & 3.932 & .025 \\
\hline Within Groups & 246.800 & 57 & 4.330 & & \\
\hline Total & 280.850 & 59 & & & \\
\hline
\end{tabular}

By looking at table 8 , it could be inferred that there were statistically significant differences between the one comparison group and the two experimental groups' mean scores on the posttest of the reading proficiency test.

As displayed in Table 9 the t-observed value for comparing the mean score of the comparison group with the combined mean scores of the two experimental groups (paper-based portfolio and electronic-based portfolio) was 2.79 ( $p$ $=.007<.05$ ). Since the probability associated with the t-value was lower than the significance level of .05 , it could be concluded that there was a statistically significant difference between the mean score of the one comparison group with the combined mean scores of the two experimental groups.

Furthermore, the first a-priori test compared the mean score of the one comparison group with the combined mean scores of the two experimental groups in order to probe the first null-hypothesis.

Table 9. A-Priori Contrast Comparison Group vs. Paper-Based Portfolio and Electronic-Based Portfolio Posttest Reading Comprehension

\begin{tabular}{|l|c|c|c|c|c|}
\hline & Value of Contrast & Std. Error & $\mathrm{t}$ & $\mathrm{df}$ & Sig. (2-tailed) \\
\hline Assume equal variances & 1.5000 & .53727 & 2.792 & 57 & .007 \\
\hline Does not assume equal variances & 1.5000 & .53592 & 2.799 & 53.125 & .007 \\
\hline
\end{tabular}


By looking at table 6, we can reach a conclusion that the two experimental groups with a total mean score of 26.3 outperformed the comparison group (Mean $=24.8$ ) on the posttest of reading comprehension. Therefore, the first nullhypothesis was rejected and it could be claimed that strategy-based instruction improved the reading proficiency ability of the Iranian EFL learners in comparison with non-strategy-based one.

To investigate the second research question, an a-priori comparison test was administered to compare the mean scores of the two experimental groups on the posttest of reading proficiency with the comparison group mean score, since a-priori allows us to compare one or a combination of many groups with one or a combination of other groups, while post hoc compares groups individually (Field, 2005).

As depicted in table 10 the t-observed value for comparing the mean score of the two experimental groups was .02. Since the probability associated with the t-value was lower than the significance level of .05 , it could be concluded that there was a statistically significant difference between the mean score of the two experimental groups on the posttest reading comprehension test.

Table 10. A-Priori Contrast Paper-based Portfolio vs. Electronic-based Portfolio Posttest Reading Comprehension

\begin{tabular}{|l|c|c|c|c|c|}
\hline & Value of Contrast & Std. Error & t & df & Sig. (2-tailed) \\
\hline Assume equal variances & .02 & .75981 & 2.63 & 57 & .793 \\
\hline Does not assume equal variances & .02 & .63994 & 3.13 & 27.970 & .757 \\
\hline
\end{tabular}

Hence, the second null-hypothesis was rejected and it could be claimed that electronic portfolio assessment improved the reading proficiency ability of the Iranian EFL students in comparison with paper-based portfolio assessment.

\section{Results and Discussion}

Based on the aforesaid discussion, we could say that there was no statistically significant difference in the reading ability of one comparison group and two experimental groups before the intervention based on their reading proficiency. However, after taking part in a 15-session strategic reading instruction the experimental groups differed statistically from the comparison group on reading comprehension exams.

Reading research in L1 and L2 has indicated that reading strategies can be taught to students and when taught they can improve students' performance on tests of comprehension (Sedighi, 1998; Farshidi, 2003).

The main finding of this study was that reading strategy instruction can significantly enhance the reading proficiency ability of Iranian EFL readers. The findings in this research are in line with those of Sedighi (1998) who studied the impacts of reading strategy instruction in EFL contexts. From these studies it was found that students' overall comprehension ability significantly improved after some sessions of treatment. Reading strategy instruction helps the poor readers to develop effective reading skills and read as professional readers do.

Janzen (2001) believes that strategic readers use different strategies and they make use of them in various contexts. Reading strategy instruction equips readers with effective techniques for dealing with written materials.

Another aim of this study was trying to indicate the instructional efficacy of electronic portfolio assessment as a tool to improve reading proficiency among Iranian intermediate EFL learners. As it was revealed in the statistical analysis and also collected data, strategy-based instruction via electronic portfolio assessment could ameliorate the participants reading proficiency at the intermediate level in comparison with paper-based portfolio and non-strategy-based instruction, which means it is the time to change the method of teaching and assessing reading to improve the English learners reading abilities. In the researchers' opinion, electronic portfolio assessment was a very fruitful way to motivate the participants to utilize technological devices such as computer, weblog, CD-ROM, and internet to evaluate their process while learning reading strategies.

In a nutshell, this study depicted that both strategy instruction and portfolio assessment, especially electronic portfolio assessment, has influence on the reading proficiency of Iranian intermediate EFL learners. The present study also showed that new methods of teaching and assessing reading could revise the traditional way of teaching reading, and using technological devices such as personal computers, CD-ROMs, weblogs, and internet are fruitful for the English learners to be autonomous and independent ones.

\section{Findings and Conclusions}

To sum up, the findings of this study state that foreign language pedagogy, especially for adult and young adult English 
learners, would reap the benefits of the inclusion of explicit and direct strategy instruction within electronic portfolio assessment.

The findings of the present article can be summarized as follows:

1. This paper revealed that teaching reading strategies is more influential than traditional methods of reading instruction. It seems that it is the time for our reading teachers to review and revise their teaching methods.

2. As it was revealed in the statistical analysis and also collected data, electronic portfolio assessment could ameliorate the participants reading proficiency in the intermediate level, which means it is the time to change the method of teaching and assessing reading to improve the English learners reading abilities. This can be done by applying different kinds of technological devices used in this study to motivate the English learners to be able to evaluate their own process.

\section{Pedagogical Implications}

The results of the present paper have some implications for English teachers teaching reading comprehension. These implications are listed as follows:

3. English instructors must use real life reading materials, such as newspaper and magazine articles, which are more challenging, rather than reading materials which are planned for the pedagogical purposes. In this study, passages from Reader's Digest magazine were used as authentic teaching materials.

4. Strategies should be taught through direct explanation, explicit teacher modeling, and extensive feedback. Furthermore, ESL/EFL learners should never be in doubt as to what the strategies are, where and why they can be used, and how they are used. More significantly, they should be informed of the value and usefulness of strategies in $\mathrm{L} 2$ reading.

5. The reading teacher in this kind of instruction assumes the role of a guide, a model, or stimulator rather than the provider of the correct answers to comprehension questions.

6. Collecting all the activities including, homework assignments and class activities while strategy-based instruction via portfolios (paper and electronic forms) enables the English learners to evaluate the one's progress during the reading course.

7. Utilizing technological devices such as personal computers, CD-ROM, Internet, and weblog can be a very good practice for those English learners who aim to participate in internet-based exams such as, IBT test. These devices enable the learners to practice individually and focus on their weak points while using technological devices.

\section{References}

Abrami, P. C., Bernard, R. M., Borokhovski, E., Wade, A., Surkes, M. A., Tamim, R., \& Zhang, Dai. (2008). Instructional interventions affecting critical thinking skills and dispositions: A stage 1 meta-analysis. Review of Educational Research, 78(4), 1102-1134.

Alexander, R. J. (1995) Versions of primary education. London: Routledge.

Ali, S. Y. (2005). An Introduction to electronic portfolios in the language classroom. The Internet TESL Journal, XI(8) http://iteslj.org/Techniques/Ali-Portfolios.html

Anderson, J. R. (1978). schema-directed process in language comprehension. In A.M. Lesgold, J.W. Pellegrino, S.D. Fokkema, \& Reading. Glaser (Eds.), Cognitive Psychology and Instruction (pp.67-82). NY: Plenum Press.

Brantmeier, C. (2005). Non-Linguistic variables in advanced L2 reading: Learner's self-assessment and enjoyment. Foreign Language Annals, 38, 493-503.

Chamot, A. U., Barnhardt, S., El-Dinary, P. B., \& Robbins, J. (1999). The learning strategies handbook. White Plains, NY: Addison Wesley Longman.

Chen, L. L. (2006). The effect of L1 and CAI on grammar learning: An Error Analysis of Taiwanese beginning EFL learners' English essays. Asian EFL Journal, 9(2), 1-19.

Day, R. R. and J. Bamford. (1998). Extensive reading in the second language classroom. Cambridge: Cambridge University Press.

Duffy, G. (1993). Teachers' progress toward becoming expert strategy teachers. Elementary School Journal, 94(2), 109-120.

Farshidi, M. (2003). The effects of separate and integrated presentation of reading strategies on the reading comprehension ability of the Iranian EFL students. Unpublished MA thesis. Tehran: Allameh Tabatabaei University.

Field, A. (2005). Discovering Statistics Using SPSS. SAGE Publications. London.

Flavell, J. H. (1992). Perspectives on perspective taking. In Beilin, H., and Pufall, P. (Eds.), Piaget's Theory: Prospects and Possibilities (pp. 109-139).Erlbaum, Hillsdale, NJ.

Janzen, J. (2001). Teaching strategic reading. In J. C. Richards and W. A. Renandya (Eds.), Methodology in language teaching and: An anthology of current practice. Cambridge: CUP. 
Nuttall, C. (1996). Teaching reading skills in a foreign language. Oxford: Heinemann.

Oxford, R. L. (2001). Language Learning Strategies. In R. Carter \& D. Nunan (Eds). The Cambridge guide to teaching English to speakers of other languages. Cambridge: CUP.

Pressley, M. (2002). Reading instruction that works: The case for balanced teaching. NewYork: Guilford Press.

Richards, J. C. \& Schmidt, R. (2002). Longman dictionary of language teaching and applied linguistics (3rd ed.). London: Longman.

Richards, J. C., \& Renandya, W. A. (2002). Methodology in Language Teaching. An Anthology of Current Practice. CUP.

Sedighi, A. (1998). The effects of training in the use of reading strategies on the improvement of reading comprehension. Unpublished Ph.D. dissertation. Tehran: Allameh Tabatabaei University.

Veenman, M. V. J. \& Beishuizen, J. J. (2004). The relation between intellectual and metacognitive skills from a developmental perspective. Learning and Instruction, 14, 89-109.

Wenden, A. L. (1991). Learner strategies for learner autonomy. London: Prentice-Hall International.

Zhang, L. J. (2002). 'Exploring EFL reading as a metacognitive experience: Reader awareness and reading performance'. Asian Journal of English Language Teaching, 12, 65-90.

Zhang, L. J. (2008). Constructivist pedagogy in strategic reading instruction: Exploring pathways to learner development in the English as a second language (ESL) classroom. 